\title{
The Stereoscope and Popular Fiction: Imagination and Narrative in the
}

\section{Victorian Home}

Jonathan Potter

Author post-print (accepted)

\section{Original citation \& hyperlink:}

Potter, J 2016, 'The Stereoscope and Popular Fiction: Imagination and Narrative in the Victorian Home', Journal of Victorian Culture, vol 21, no. 3, pp. 346-362

https://dx.doi.org/10.1080/13555502.2016.1192559

DOI 10.1080/13555502.2016.1192559

ISSN $1355-5502$

ESSN 1750-0133

Publisher: Oxford Academic

Copyright (C) and Moral Rights are retained by the author(s) and/ or other copyright owners. A copy can be downloaded for personal non-commercial research or study, without prior permission or charge. This item cannot be reproduced or quoted extensively from without first obtaining permission in writing from the copyright holder(s). The content must not be changed in any way or sold commercially in any format or medium without the formal permission of the copyright holders. This document is the author's post-print version, incorporating any revisions agreed during the peer-review process. Some differences between the published version and this version may remain and you are advised to consult the published version if you wish to cite from it. 


\begin{abstract}
$\underline{\text { Abstract }}$
The stereoscope was a popular parlour toy that provided a powerful psychological viewing experience in the heart of the domestic space. In this article, I consider the stereoscope's position as an instrument that was experienced, and often represented, in relation to the imaginative narrative processes of memory and fantasy. By reading the stereoscope's position within popular fiction, the article seeks to uncover the way in which the stereoscope was consumed. The article shows that for many in the mid-Victorian period, the stereoscope operated as an everyday narrative-forming experience with a strong relation to the popular periodical fiction that was read alongside it in the domestic space. The first section of this article considers the cultural and psychological position of the stereoscope within the home, reading this alongside a number of short stories published in the popular periodic press. The second section consists of an analysis of the stereoscope's involvement with psychological dualism and self-doubling, issues which stem, in particular, from the device's reliance on photography. These aspects of the device are explored in relation to a nineteenth-century short story which draws a problematic relation between one's self and one's portrait. Finally, the article finishes by drawing these issues together to consider the importance of imaginative narratives within the stereoscopic experience. The viewing conditions of the stereoscope encouraged viewers to engage in an anticipatory, open-ended, and imaginative fantasy narrative. It is this unique narrative character of stereoscopic viewing experiences which most prominently distinguishes the device from other visual media.
\end{abstract}

Keywords: Stereoscope, Popular Fiction, Narrative, Fantasy, Memory, Photography, Short Stories, Periodicals, Optical Toys, Domesticity.

Word Count: 7, 666 (with footnotes); 7,036 (without footnotes). 


\section{The Stereoscope and Popular Fiction: Imagination and Narrative in the Victorian Home}

The stereoscope was a popular nineteenth-century device that used the principles of binocular vision to create a sense of depth from flat images. This description captures the original intent of the stereoscope's inventor, Charles Wheatstone, who conceived it as an instrument of scientific demonstration. More than this, however, as a popular parlour toy it provided a powerful psychological viewing experience in the heart of the domestic space. In this article, I consider the stereoscope's position as an instrument that was experienced, and often represented, in relation to the imaginative narrative processes of memory and fantasy. The stereoscope was a technology of the imagination that facilitated, articulated, and even conceptualised the fantasy of the observer. As will be demonstrated, this experience of the device was portrayed and reiterated in fiction and non-fiction that appeared in popular periodicals. As a part of a wider array of technologies (visual and otherwise) that intersect with everyday imaginative processes, many of the issues involved intersect and overlap with those of other technologies, most notably photography, but also printed texts themselves (books but also magazines and newspapers). However, the stereoscope's unique viewing properties, and its prevalence within Victorian homes, give it a special cultural resonance which distinguishes it from other media. Examining visual technology and literature in relation to one another has elicited valuable insights that inform our understanding of literary texts but also of the culture and society that produced them. ${ }^{1}$

The purpose of this article is to use examples of fictional stereoscopes to examine the technoimaginative position of the device within Victorian culture. The first section of this article, then, considers the cultural and psychological position of the stereoscope within the home, reading this alongside a number of short stories published in the popular periodic press. The second section addresses the broader reception of the stereoscope through analysis of the stereoscope's involvement with psychological dualism and self-doubling, issues which stem, in particular, from the device's reliance on photography. These aspects of the device are explored in relation to a nineteenth-century short story which draws a problematic relation between one's self and one's photograph. Finally, the article finishes by drawing these issues together to consider the importance of imaginative narratives within the stereoscopic experience. The viewing conditions of the stereoscope encouraged viewers to engage in an anticipatory, open-ended, and imaginative fantasy narrative. It is this unique narrative character of stereoscopic viewing experiences which most prominently distinguishes the device from other visual media. 


\section{Seeing Double}

The stereoscope was an instrument very much of the domestic sphere. The still life in figure 1, itself a stereograph, gives an indication of how the stereoscope might fit within the Victorian domestic space. The painting, notably, is half covered and relegated to the background. At the forefront, on the table next to a photographic album and a statuette of an angel, sits the stereoscope, its images invitingly visible to the viewer, like two small windows. Tom Gunning notes that

the nineteenth-century parlour became not only the protective shell one fashions for oneself but also the locus of optical devices and philosophical toys of all sorts - the stereoscope, the kaleidoscope, the magic lantern — that seem to open the viewer's gaze onto a different world, but only under the dominion of the image and semblance. ${ }^{2}$

Images like this still life articulate the visual character of the parlour. It is a place of show, in which social status such as affluence or respectability might be indicated by the objects exhibited, but it is also a place of show in the sense that a wealth of images are made available to the imaginative gaze. Positioned within this space, the stereoscope is part of a media landscape of optical and psychological spaces produced by, and relating to, other technologies and devices including traditional painting, magic lanterns, photography, the kaleidoscope, and so on. Though many of its features and characteristics overlapped with those of other devices, the stereoscope's peculiarly private, lifelike images were unique within this landscape.

Part of the popularity of the domestic stereoscope arose from the sheer variety of options available. Prices in the mid-1850s ranged between twenty guineas and two shillings, depending on the quality and type of set one bought, and there was a vast array of different genres and subjects of slides available. In terms of size, one could purchase small hand-held stereoscopes or large column stereoscopes which, as Plunkett describes, were 'more home-entertainment systems than cheap portable toys'. ${ }^{3}$ This level of variety meant that, whilst the basic technology was within the financial reach of a vast number of households, the market maintained an appeal to the middle and upper classes as a way of exhibiting their higher social status through larger, more extravagant versions of the device, as well as a device for viewing images.

The stereoscope has generally been understood in terms of its explicit destabilisation of the relationship between solidity and perceptual reality, involving it in often high-level religious and philosophical debates. In philosophical and scientific discussions the issues surrounding the stereoscope were epistemological and centred on its apparent creation of substance from nothing. 
Traditionally, when one viewed a depiction of a thing, one was alerted to this by the flatness and materiality of the image. But in the stereoscope one saw solidity even though, looking at the device itself, it was immediately apparent there were only the two flat cards. For these reasons, debates tended to be centred around the possibility of visually accessing any real depth or distance or whether vision is able only to perceive what one article calls 'the visible signs of solidity'. ${ }^{4}$ Kant had argued that form and space were mental constructs, and the stereoscope would seem to have confirmed that. According to John Plunkett in his examination of the differences between Wheatstone's and Brewster's differing accounts of the stereoscope, scientific and popular discourse on the stereoscope was 'fissured between two contrasting approaches: one was broadly empirical, idealist and phenomenological; the other was nativist, material and geometrical'. ${ }^{5}$ On the one hand, there was the argument that depth and solidity could be perceived directly by the eye, and on the other hand, there was an argument that depth and solidity were perceived through psychological or metaphysical processes.

Moreover, the stereoscope was involved in the intersections between theology and science. As Hankins and Silverman describe, both scientific and popular accounts of the stereoscope were informed by a 'network of natural theological presuppositions' which 'established the human eyes as the ideal instrumentation for visual representation'. ${ }^{6}$ Involved in this conception of the human eye was the belief of natural theology that the human eye's supposed perfection was proof of God's existence. For example, the Philadelphia photographer John F. Mascher, proclaimed in 1855, 'it is only the hand of Omnipotence that could that could have designed and constructed such a wonderful organ'. ${ }^{7}$ Mascher, coming from this presupposition, argued that camera lenses must be made the same size as the human pupil and that the distance between the lenses used to take the two stereoscopic images must be exactly two and a half inches to simulate the distance between a pair of human eyes. Stereoscopic vision is thus attempted as a simulation of human vision which, based on the supposition of its divine origin, was held as the ideal model of visual perception. However, whilst such understandings of the device are obviously important, they tend to overlook the everyday experience of stereoscopic vision which tended to be domestic, private, and often imaginative.

This kind of viewing is described in an article in The British Mothers' Journal:

After tea, when the conversation was beginning to flag a little, Mrs. Henwood brought out a very beautiful stereograph which had been sent to her from Australia, one of the kind denominated by amateur photographers a 'glass positive' [...] It was a beautiful picture $[\ldots]$ and, perhaps, more beautiful to us, because our eyes were never likely to look upon the reality. ${ }^{8}$ 
Here we can sense the suggestiveness of the image - the power of the leisurely gaze at images never to be seen in life. The experience is within a communal setting but the act itself is inherently private - only one person can look through the stereoscope at a time. The viewing conditions allow for the gaze to be as concentrated and as extended as the viewer desires. Such conditions are important in the cultural role of the stereoscope and are starkly contrasted by the public stereoscopic experience of the Kaiserpanorama in the 1880s. In the Kaiserpanorama up to twentyfive spectators could view different stereoscopic images which would be rotated every two minutes. Jonathan Crary argues that it is a space in which the physical and temporal alignment of body and machine correspond to the rhythms of factory production and to the way in which novelty and interruptions were introduced into assembly-line labour in order to prevent attention from veering into trance or daydream'. ' In comparison, a 'trance or daydream' is exactly the kind of state that might be attained when privately viewing a stereograph in a comfortable parlour during an hour of leisure after tea.

Crary's description of stereoscopic vision emphasises perspectival disparity and the stereoscope's 'derangement of optical cues' wherein the depth of the stereoscope has 'no unifying logic or order [...] The reading or scanning of a stereo image [...] is an accumulation of differences in the degree of optical convergence, thereby producing a perceptual effect of a patchwork of different intensities of relief within a single image'. ${ }^{10}$ David Trotter builds on this to suggest how the unique perspectival character of stereoscopic images allowed for an observational absorption and disconnectedness that was suggestively analogous with early cinematic close ups. ${ }^{11}$ The stereoscope, in Trotter's description, uncovers elements wholly unexpected when one looks at the flat image of the visible - rather than necessarily being attracted to the central subject of the image, when viewed stereoscopically the eye is drawn towards the objects of contingency which float towards the observer from the foreground. This effect, Trotter argues, is deliberately emphasised in some stereoscopic views. In essence, these are images which draw the viewer in, which seem open to the physical grasp, and which contain a private stillness and timelessness. The stereoscope focussed the glance into an intense gaze of imaginative power; it was a technological intervention into reveries and daydreams that could act as prompt, guide, or facilitator for imaginative selfexpression. These kinds of viewing experiences were both private and individual, contrasting strikingly with Wheatstone's intention to openly exhibit universal principles of binocular vision.

The stereoscope's viewing conditions offered, as Lynda Nead contends, 'the possibility of total immersion in semi-private sexual reverie'. ${ }^{12}$ This kind of experience is fictionalised in a short story from Sharpe's London Magazine, offering us a useful indication of how these private visions might have been experienced. The story, simply titled 'In a Stereoscope', tells of a romantic fling 
with a 'little Spaniard' which, with unsettling and phantasmagorical language, is broken up by a mysterious masked man at a ball. Aside from the title, it is only at the story's end, when the narrator wakes up, that the story is explained as a dream prompted by a set of stereographs:

Strange! I must have been dreaming; and if I have been talking in my sleep, there will be the deuce to pay with your aunt - though Heaven knows I never was in Spain, as sure as my name is Smithson Brown, and never kissed a black-eyed woman in my life. [...] Here, take away the stereoscope, my dears, and the pictures that I fell asleep over, after they put so much folly into my old head. Put away the Spanish Girl, and Dressing for the Ball, and that foolish, Moonlit Balcony [...] and never tell your aunt what nonsense your uncle talked in his sleep, after seeing your. ${ }^{13}$

The stereoscope's relation to the imagination is the very basis for the story. Part of the stereoscope's fictive suggestiveness is in its technological process which relies on the psychological composition of two images into one - a process recast as a sexual coupling in one cartoon from Vanity Fair which showed a young gentleman explaining to an apparently innocent young lady that the 'principle of the stereoscope' was to 'make two people into one'. ${ }^{14}$ In this way the stereoscope, for all its apparent solidity and reality, held a narrative-building quality. Henry Morley and William Henry Wills in Household Words, for example, describe how the two images on the stereoscopic card created an entirely imaginary composite image. The images might, for instance, show two men fighting - each image showing a different figure so that:

In looking at this group, and at the same time rapidly moving to and fro a small slide behind the glasses, which covers now one eye and now another, the two impressions run into each other and produce the appearance of an active sparring match. ${ }^{15}$

This process, made explicit by Morley and Wills, was implicitly continued in the way an individual viewing a set of different stereographs might collate the images into a narrative story. This was facilitated by the private nature of the viewing experience; unlike technologies which were viewed as part of a show, like the magic lantern or moving panorama, for instance, there is little or no direction given on how the image should be viewed (although some stereographs had a caption or brief description on the reverse side). Without a showman, lecturer, or guidebook (as in the static panorama, for example), the individual is left free to construct his or her own narrative around the images. The private nature of the device, too, allows the viewer time and psychological space to construct their own narratives around the images, which were often sold in thematic sets. While these thematic sets may themselves loosely guide or propel a narrative if viewed in sequence, formalised serialisation as in, for example, a serialised story, is not a strong feature here because the viewer retains control without the fear of destroying an already fixed narrative. 
The result of this private narrative-creation in the story is uncanny as the fictional viewer unconsciously attempts to transcribe the unfamiliar into the familiar through his dream. This is emphasised in the narrator's description of his inability to recognise his rival:

'Didn't you recognise him? Why, he knew you at once, in spite of your priest's dress [...]

I suppose he looks like -

Like whom? Why had I no strength to ask when she faltered and hesitated? ${ }^{16}$

The images repeat the past in ways which are both familiar and unfamiliar, which provoke a memory response but, not tied to actual memories, cannot complete the link. If memory is itself a kind of psychological narrative process (experiences being reconstructed with each remembrance), then the stereoscope mimics this to some degree. ${ }^{17}$ That is, the stereoscope forms imaginary narratives around photographic images which are a kind of archival evidence of the past (even if it is not a past personally experienced). Interestingly, the erotic potency of this kind of fictive memory-creation is such that, even though the narrator has not actually done any of the things the story describes, he is still anxious to denounce it as 'nonsense' and hide it from his wife lest there be 'the deuce to pay'. ${ }^{18}$ The story obviously draws humour from this, but the joke belies an underlying tension about memory, desire, fiction, and reality.

On top of the importance of psychological processing in the viewing experience, the stereoscope's portrayal in the general press further cemented its position across the divide between the technological and the imaginative. Outside of the high-level debates about philosophy, religion, and science discussed above, descriptions of the device emphasised the uncanny and the supernatural. Morley and Wills, for example, begin their article on the stereoscope by speculating that

Everyone has been told that the old priests of Egypt and of Greece were better skilled in optics than in necromancy; that many an awful ghost, riding upon a cloud, was the result of hocussing and focussing. Any commentator is entitled to suppose that an old form of incantation (said to have had a more sacred origin) has become slightly corrupted by the exchange of convertible letters in the lapse of time, and was in the first instance, really hocus, focus $[\ldots] .^{19}$

This speculation linking ancient 'necromancy' and 'awful ghosts' to modern optics clearly places the device on the epistemological border between the supernatural and the natural, a position that photography already held within debates about science and religion.

The stereoscope's physical position within the home gave it a greater psychological significance. The home, as Gaston Bachelard argues, is a space closely entangled with the daydream: 'the sheltered being [...] experiences the house in its reality and in its virtuality, by means 
of thought and dreams. ${ }^{20}$ The stereoscope's entrance into this space can be understood as the physical arrival of an object of display into a familial exhibition space or as the intervention of a virtual technology into the psychological space of daydreams. The haptic quality of the stereoscopic image is important here as it traverses these two conceptions of domestic space. Patrizia Di Bello, charting the relationship between touch and nineteenth-century femininity, writes that:

$[\ldots]$ nineteenth-century feminine culture endowed women's touch with almost magic powers $[\ldots]$ Women's hands changed the meaning of objects, from commodities valued by price, into fetishes endowed with affective powers. Re-made by the hands of the women of the house into freely bestowed gifts, objects in the home were cleansed of the alienating relationships engendered by the factory and the market place. ${ }^{21}$

Di Bello describes how women's magazines featured instructional articles on adding colour to photographs, using photographs to aid painting, and the making of photographic albums. ${ }^{22}$ These are all transformational activities which utilise women's touch to transform machine-made photographs into what Di Bello calls 'fetishes endowed with affective powers'. These processes all involve the integration of an object with a certain narrative of feminine domesticity. Objects are 'cleansed of $[. .$.$] alienating relationships' and are integrated within the domestic narrative of$ personal relationships and emotional security. Touch and women's handiwork, in this way, intercedes between the material and the emotional. The stereoscopic image, intrinsically linked to touch through its suggestion of depth, came pre-endowed with this affective power in a way which surpassed that of the common photograph. The observer gazing into the stereoscope is invited into a visual space that, ideally, intertwines physical reality with the emotional and psychological dimensions of domesticity. Crary's argument that Brewster's version of the stereoscope allowed for a greater degree of illusion than Wheatstone's stereoscope (and later, the Holmes stereoscope furthered this change) is, again, suggestive of the importance of a quasi-mystical affective power involved in the viewing of the stereograph. ${ }^{23}$ Because Brewster's stereoscope, the version that popularised the device, hid the technological apparatus inside a box with only the lenses visible, the device carried a greater suggestive power than Wheatstone's device which, rather than hiding the scientific principles involved, actively illustrated them. In the terms that Di Bello uses, the combination of rational processes which create the image but ultimately alienate the observer, is hidden and its absence allows for greater psychological suggestibility. The stereoscope possessed an ability to affect the viewer, to provoke daydreams and stimulate the imagination and acquire an emotional power, in ways which surpassed those of the ordinary photograph and which had the potential for subverting traditional notions of domestic stability. 
This sense of dangerous intrusion is articulated in a short story published anonymously in 1859 in The Ladies Cabinet of Fashion. The story tells of a young sailor, James, who leaves his fiancée to go to sea, after which, he promises, he will make no more voyages and they can be married. Before he goes, he views a stereoscopic image of his fiancée, Alice, exclaiming 'How like you this is [...] I shall take this with me [...] I know I shall catch myself talking to this bit of glass, and trying to comfort it'. ${ }^{24}$ The stereoscope offers an image so life-like that it will act as a surrogate while he is away. A fact which is then reiterated when he looks at his own image and tells Alice, 'As long as you see this lubber here look as strong and hearty as he does now, you may be sure, Alice, that I am all right. You must peep into this stereoscope as into a magic-glass'. ${ }^{25}$ This faith in the reality of the photograph eventually results in tragic consequences during the story's conclusion at a magic lantern show taking place at Alice's familial home for a child's birthday party. The magic lantern show, in this context, was a kind of family-friendly version of the earlier phantasmagoria that functioned like a pantomime of traditional and well-known ghost stories with accompanying images. As the show progresses, the lanternist, after running through the ghosts the children expect, projects James' image at the very moment the narrator (a family friend) is about to break the news of a bad storm with as yet unknown consequences to Alice:

On the disc was gradually coming forth a great white face. The vivid colours of the old ghost picture died away as the livid hues of this face became stronger. The eyes seemed dead or closed, the outlines were undefined, the mouth was rigid. The face was of gigantic proportions, and was the most corpse-like and horrible picture I have ever seen; but it was the face of James. [...] without thinking any evil, [the lanternist] had used the photograph of James as a slide for the magic-lantern. It was one of those transparent photographs on glass, so often used in stereoscopes. ${ }^{26}$

The image causes Alice to collapse and, as the final line of the story dramatically concludes, the returning James 'had escaped the perils of fire and sea, and came back to find Alice dead.$^{27}$

The story explicates the expectations viewers might have as they transition between different visual modes. Looking through the stereoscope, the characters expect and comprehend a depiction of reality so convincing that it might, temporarily, stand in for the real thing. Looking at the projections of the magic lantern, they expect to see the fantastical images of ghosts and the undead that were traditional in the phantasmagoria. When these two visual modes are combined then the result is a visual confusion for which the observers are not prepared. The suggestion is that, rather than having been trained by magic lantern shows to recognise illusions and tricks, they have been conditioned to see exclusively ghosts within the safe confines of the magic lantern show. The experience of the show acts as a kind of framing device which delineates a remove from reality 
into a space in which supernatural events are, temporarily at least, not only plausible but expected. The insertion of the photograph into this context throws the viewer's sense of safe remove into confusion and doubt. Put another way, having been encouraged by James to consider it as his double so that when she sees the photographic double look as strong and hearty as he does now, you may be sure, Alice, that I am all right', Alice has created a narrative of safety and security around the stereograph. The viewing conditions of the stereoscope encourage a prolonged and involved gaze that creates powerful imaginative resonances between viewer and image. When this narrative of safety becomes entangled in the deathly narrative of the magic lantern show, the psychological effect is profound. The story evokes this melodramatically but it serves as an incisive example of the psychological dynamics involved in looking through the stereoscope.

The story is thematically similar to 'In a Stereoscope' in its interest in romantic and sexual relationships through the stereoscope - it is important to note that the two characters admiring their stereoscopic images of each other are lovers. The stereograph creates an implication of touch, of tangibility, to the flatness of the photograph and allows the viewer the teasing sensation of being able to reach out and touch the subject. Oliver Wendall Holmes in his essay of 1859, states:

The mind feels its way into the very depth of the picture. The scraggy branches of a tree in the foreground run out at us as if they would scratch our eyes out. The elbow of a figure stands forth so as to make us almost uncomfortable. ${ }^{28}$

The tactility of the image, the haptic quality, is the most prominent feature of the stereograph. For the lovers in the story, this must have been a part of its appeal - the sense that one's absent lover is within reach. In the story Alice takes the portrait 'up to her little room, and treasured it there', and after James departs, Alice 'retired in company with the portrait for most of the morning'. ${ }^{29}$ This privately enjoyed surrogate is viewed frequently, and becomes a source of comfort even in the middle of the night, when she woke from some terrible dream'. The removal of the stereoscope to the even more private realm of the bedchamber, the underlying illicitness of night time, and the tactility and subject of the image, show the erotic charge of the stereoscopic image.

\section{Being Double}

Speaking to oneself, another private act of doubling and narrative, is discussed in an article in Household Words:

Talking to one's self may also be the result of what has been called the dualism of the mind.

There are moments when we are conscious of having two selves, as it were; just as there are times when our bodily eyes see double: one self addresses itself to the other self, 
remonstrates with it, reasons, argues, or condoles with it. St. Paul eloquently describes this psychical condition in the passage where he laments 'that which I do, I allow not: for what I would, that I do not; but what I hate, that I do.' There is going on within us a sort of 'choice of Hercules.' This, then, is a true conversation, and continues to be so, until the two intellectual halves of our nature converge and combine, like the double picture in a stereoscope, into one. Our soul then becomes a unity, and we no longer talk to ourselves, but either remain silent, or address our observations to others. Also, this phenomenon occurs only under circumstances of great mental agitation, internal struggle, or passionate excitement. $^{30}$

The dualism of the self is a dialogue between two halves. When unity is achieved the dialogue falls silence and 'we no longer talk to ourselves'. The stereoscopic image, of course, is also a conjugation of two halves (the two images forming one). The stereoscopic image of the self (as in the story about Alice and James) is a conjugation which appears whole, but is actually separated from its true counterpart - the actual self. Visually at least it appears to be a part of the self, a duplicate or an extension of the physical presence of the self, so that Alice is able to imagine that it really is the safe and healthy James she views. But the image obviously exists separately, operating away from the self so that communication between the two only occurs at the moment of separation when the image is recorded on the photographic plate. The stereoscopic portrait is the silent double that refuses any dialogue beyond the one-way discourse of a longing gaze.

This problematic relation, whilst exacerbated by the stereoscope's viewing conditions, exists in wider photographic contexts too. Once the image has been created, the image stands in for one's self in any narratives formed around it. Even though these narratives might then be transposed on to the real person in the mind of the observer, the person viewed is only a silent character in that narrative. This was perhaps especially troubling for women who, as Patrizia Di Bello points out, 'accomplished femininity' might equally be 'a pose to fashion oneself as desirable' or 'a way to express oneself. ${ }^{31}$ The portrait might offer an avenue for self-expression but it also held the potential for a commercialised selling of women's images outside of the narrative context initially intended. A fact demonstrated by Charles Allston Collins' (younger brother of Wilkie Collins and Charles Dickens' son-in-law) short story, also in Household Words, entitled simply 'Her Face' (1858). Collins' story is a first person narrative in which the narrator sees 'the sweetest face imaginable — and the most feminine' in 'a cheap photograph [...] in a street-door case, with a touter lying in ambush'. 32 'Haunted' by the face, during a period of flaneur-like wandering through the city he spies the real young woman and follows her home. Strikingly, the narrator is himself paranoid about being observed: during a passage in which he stands outside her house, he notes 
all the other people on the street and is 'obliged to take myself off, and leave my observers masters of the field'.$^{33}$ Later, when he attends a dance he believes she will be at he is confronted with young ladies who 'took note of me, with covert whisperings and gigglings, to my soul's confusion' ${ }^{34} \mathrm{He}$ is not put off when it becomes evident that the woman, named only as 'Miss Fenton', has detected him following her and instructed her servant to lie to him when he knocks of the door of her residence and asks about her. Instead of being deterred, he admires her more, for it 'showed a modesty and difficulty of access, which was a good sign'. ${ }^{35}$ Indeed, when they finally do briefly meet, she immediately recognises him and flees the room. The story ends with the arrangement of their marriage through her father, despite the fact they still have yet to engage in a single conversation. With only her father's surname to identify her, 'Miss Fenton' remains an elusive and almost entirely absent character. Having been introduced by her photograph, she is never characterised beyond the silent, static image, and the narrator never seems interested in anything more than what is contained in the image - the photograph is the sum total of the male suitor's interest in her and their complete lack of interaction (aside from his persistent stalking and her attempts to avoid him) is of little concern to him.

An obvious reading of this story would be as a demonstration of the masculine gaze and the commodification of women through their images. Stereographs, alongside carte-de-visites and other photographic images, were commonly displayed in shop windows that, as a commodified form of display, were at the heart of concerns about obscenity. Certainly, there was a link between stereoscopy, sexual desire, and gender roles. Colette Colligan discusses, for example, the explicit pornographic images that were prolifically produced and consumed. ${ }^{36}$ And within the bounds of legality and respectability, images of private moments and intimate domestic scenes featuring women were common. Whilst these issues were not unique to the stereoscope, they were clearly involved in its cultural position. However, rather than concentrating on the male narrator's gaze, I want instead to approach this relation by considering the story from Miss Fenton's perspective. She is not permitted a narrative voice or, indeed, any voice at all, but has been replaced by her silent photographic image. She has, it seems, no control over the consumption of the (her?) image or its meaning(s); within the fictional framework there is, in effect, no dialogue between the real woman and her technological double. There is silence but it is not a silence of unity, rather it is the silence of a severance between image and substance, between external body and psychological self. It is a silence of death; Miss Fenton's agency over her own narrative has been overpowered by the exposure of the image. Any control or power to affect the meaning or interpretation of the photograph (which leaves itself dangerously open to meaning) was diminished at the moment of its inception so that it becomes a commercialised object open to aggressive predatory narratives 
that silence self-expression. A narrative is formed around the image but the actual Miss Fenton is a silent character swept helplessly along by the narrative which is external and beyond her control. If a chance glance at a photograph can have this effect, the power of prolonged, private attentions through a stereoscope become dangerous indeed. This doubling is dangerous for the silenced young woman in 'Her Face', but it is deadly for the young woman in 'The Photograph'.

The eroticism of the image Alice has of her sailor fiancé is a mark of its imaginative power. But there is a danger in this eroticism that resides in the fallaciousness of the image. It is not the young man who invades Alice's bed chamber, it is simply his likeness. If we understand a ghost to be the re-embodiment of a past self (either one's self or the self of another), then the photograph cannot avoid a spectral association. The photograph gives body, at least in a visual sense, to the past, but it does so in a way that inverts the traditional notion of the ghost. Instead of a reembodiment of the spirit, photographs are the removal of spirit so that only the body remains. It is bodies from the past which one views, not spirits from the past. It is perhaps this which makes, to modern sensibilities at least, Collin's story 'Her Face' so chilling - the narrator's obsession with a woman's photograph presents her as a body which he can imaginatively (romantically and erotically) fill with his own desires, negating her selfhood from the narrative entirely. The imaginative viewing of the observer thereby overpowers the ontological security of the observed. In Alice's case this is more palatable because the narrative imposed by the viewer (Alice) corresponds with (and was invited by) the self-narrative of the portrait's original (James). However, because this is a relation between two psychological narrative processes, we might then ask whether the image Alice views in her bed chamber is a double of her fiancé or a double of herself? It is his body she sees but it is her imagination that imbues it with spirit and makes the image so arresting.

\section{Past, Present, Imagined: Memory and Fantasy in the Stereoscope}

The stories discussed above give us clues as to how the stereoscope might be received by individuals as an instrument of the imagination. It is not a coincidence that these stories are so intimately involved with the stereoscope; the act of fiction writing was itself associated with the stereoscopic viewing experience. Images, like texts, have a tense. Photographs and stereographs, like textual narratives, have an implicit end point in that they are created from a temporal as well as spatial point of view. ${ }^{37}$ Just as the photographer looks out through the lens, the image looks backward to the moment in which it was taken. The image presents a recuperation of a present that is now past. Although the viewer/reader usually experiences them in a forward motion, the 
narratives formed by stereographs and printed fiction are self-consciously restaging the movement of a timeline from its endpoint. In the image, this is less constrained, less forceful, as the viewer is free (even encouraged) to stray beyond the moment preserved in what they see to imagine what might happen next. In the printed story, the past and the future are fixed by the text, with the present experienced as a progression through these fixed points. ${ }^{38}$ Although narrative points us backwards from a fixed point, it also points us forward because, as readers moving through narrative in a pseudo-chronological progression, we are drawn forward, anticipating the next present moment. In the case of a story, this drawing forward has a certain fixed rigidity in that these narratives terminate at the predetermined end of the text. However, looking through the stereoscope, a private, prolonged, and engrossing way of looking, the viewer is encouraged to move beyond the fixed narrative moment in the image to generate personal, localised narratives through daydreams and fantasies. Stereoscopic images evoke a sense of the past but they also draw the viewer in, via a sense of depth and reality, to a present (the present that has passed), and move beyond this to anticipate (but never fix or determine) an imagined future. In other words, the image presents a past that anticipates a future that is left available to individual acts of imagination. In this way, the device operates within a narrative framework that involves itself with daydreams and fantasies.

The stereoscopic viewing experience begins with an image and is free to return to the image at any given moment, but it is also uniquely conducive to imaginative straying from the path established by fixed narratives. Looking at a photograph without a stereoscope might provoke the memory, it might prompt a daydream, but the effect was lessened by the photograph's presence in conventional reality, the availability of the image to other onlookers, and the more distracted gaze of the viewer (whose attention might easily be arrested by objects and events outside of the photograph). Looking at a stereograph (likely to be photographic itself) through the stereoscope, the viewer is removed from the visual sensations of conventional reality and invited into a space where objects conform to a different kind of perspective (as Crary and Trotter describe above). Because of its viewing conditions, looking into the stereoscope was not as passive an act as, for instance, looking at cartes-de-visites might be, but was an active, narrative-forming process involving the imagination and analogous to acts of remembering.

In many cases the stereoscopic image recuperates a past not personally experienced (a past received only through the image or text). In these cases, there is the temporary resonance of memory precisely because of the stereoscope's power to drive the imagination forwards, to suspend ordinary cognitive experiences of reality and sweep the viewer/reader up in fictional narratives. The illusive, imagined memory-narrative suggested by the image is dispelled at the point 
at which reality breaks into the narrative and disrupts this drive. When one looks away, the dominance of conventional reality is restored.

This is articulated by G.H. Lewes' his essay on Charles Dickens. G.H. Lewes writes of the power of Dickens' imagination: '[...] in no other perfectly sane mind [...] have I observed vividness of imagination approaching so closely to hallucination'. ${ }^{39}$ Lewes forms a distinction between imagination and hallucination that hinges on the ability of the observer to correct erroneous perception through experience:

$[\ldots]$ if I see two plane images in a stereoscope, it is impossible not to have the feeling of seeing one solid object. But these beliefs are rapidly displaced by reference to experience [...] I know the seeming solid is not an object in relief, but two plane pictures. It is by similar focal adjustment of the mind that sane people know that their hallucinations are unreal. $^{40}$

Fiction, hallucination, and the stereoscope are all caught up in a psychological process of perception that can either be imaginatively controlled or morbidly controlling. One could become lost in fictional narratives if not careful of imaginative illusions. In a way, the stereoscope's technological apparatus operated as a perceptual safety net, marking a clearly defined edge between reality and imagination. One sensed the image as one might sense an hallucination, with all the outward appearance of reality alongside the possibility of fantasy and daydream. However, the material presence of the stereoscope ensured that one was always aware of the unreality of the image and of the physical presence of his or her own being in relation to this. Whereas stereoscopic images of oneself might be problematic, for the detached observer the device itself gave a sense of ontological certainty - it reinforced a sense of the physical body in relation to the intangible image, thereby grounding the mind in physical reality. The observing body was anchored in reality, as it were, by the physicality of the device. In this way the stereoscope performed an important function for an age where the perils of the imagination were open to serious consideration; it created a safe space within the domestic environment for daydreams and fantasies. Equally, however, it allowed the individual a kind of imaginative parole from the confines of social convention or physical possibility. Daydreams and fantasies prompted by even the most respectable stereoscopic images might be incorporated into subversive personal narratives, and images of inaccessible places rendered visual knowledge accessible to those unable or unwilling to access it in situ. Understanding the stereoscope's cultural impact is not just a question of its role in popular science or philosophy, or even of unravelling a binary power structure of observer and observed, but requires opening up to analysis the intersections between the technological stereoscope and the imaginary stereoscope, between the image as it was (flat, two dimensional, 
photographic) and how it might be seen (three dimensional, imbued with memory/fantasy, emotionally evocative).

${ }^{1}$ For notable examples, see: Isobel Armstrong, Victorian Glassworlds: Glass Culture and the Imagination 18301880 (Oxford: Oxford University Press, 2008); Nancy Armstrong, Fiction in the Age of Photography: The Legacy of British Realism (London: Harvard University Press, 2002); Alison Byerly, Are we there yet? : Virtual Travel and Victorian Realism (Ann Arbor, MI: University of Michigan Press, 2013); Thomas L. Hankins and Robert J. Silverman, Instruments and the Imagination (Princeton, New Jersey: Princeton University Press, 1995); Erkki Huhtamo, Illusions in Motion: A Media Archaeology of the Moving Panorama and Related Spectacles (Cambridge, MA: MIT Press, 2013); Daniel A. Novak, Realism, Photography, and Nineteenth-Century Fiction (Cambridge: Cambridge University Press, 2009).

${ }^{2}$ Tom Gunning, 'The Exterior as Intérieur: Benjamin's Optical Detective', boundary 2, 30, 1 (2003), 105-130 (p. 107).

${ }^{3}$ John Plunkett, 'Depth, Colour, Movement: Embodied vision and the Stereoscope', in Multimedia Histories: From the Magic Lantern to the Internet, ed. James Lyons and John Plunkett (Exeter: University of Exeter Press, 2007) pp. 117-131 (p. 122).

4 'ART. VII. - Sight and Touch: An Attempt to Disprove the received (or Berkleian) Theory of Vision. By Thomas Abbott, M.A., Fellow and Tutor of Trinity College, Dublin. Illustrated with Woodcuts. London, 1864.' (Review) in The North British Review, 41, 81 (August 1864), 199-230 (p. 225).

5 John Plunkett, “'Feeling Seeing”: Touch, Vision and the Stereoscope', History of Photography, 37, 4 (2013), 389-96 (p. 394).

${ }^{6}$ Thomas L. Hankins and Robert J. Silverman, Instruments and the Imagination (Princeton, New Jersey: Princeton University Press, 1995) p. 152

${ }^{7}$ J.F. Mascher, 'On Taking Daguerreotypes without a Camera', Journal of the Franklin Institute, 59 (1855) 34447 (p. 346) <http://www.sciencedirect.com/science/journal/00160032/59/5> [accessed: 27 November 2013].

8 'The Fancies of a Maiden Lady', The British Mothers' Journal, [Date Unknown].

${ }^{9}$ Jonathan Crary, Suspensions of Perception: Attention, Spectacle, and Modern Culture (Cambridge, Mass.: MIT Press, 2001) p. 138.

${ }^{10}$ Crary, Techniques of the Observer, p. 125.

${ }^{11}$ See David Trotter, 'Stereoscopy: modernism and the "haptic", Critical Quarterly, 46, 4 (2004), 38-56.

${ }^{12}$ Lynda Nead, 'Strip', Early Popular Visual Culture, 3, 2 (2005) 135-50 (p. 138).

${ }^{13}$ Leslie Walter, 'In a Stereoscope', Sharpe's London magazine of entertainment and instruction for general reading, August 1864, 83-89 (p. 89).

14 'So Like Matrimony', Vanity Fair, 7 July 1860, p. 18.

${ }^{15}$ Henry Morley and William Henry Wills. 'Photography', Household Words, 19 March 1853, 54-61 (p. 60).

${ }^{16}$ Walter, p. 86.

${ }^{17}$ For a useful discussion of memory as narrative (both psychological and textual) see Mark Freeman, 'Telling Stories: Memory and Narrative', in Memory: Histories, Theories, Debates, ed. Susannah Radstone and Bill Schwarz (New York: Fordham University Press, 2010) pp. 263-77.

${ }^{18}$ Walter, p. 89.

${ }^{19}$ Henry Morley and William Henry Wills, 'The Stereoscope', Household Words, 10 September 1853, 37-42 (p. $37)$.

${ }^{20}$ Gaston Bachelard, The Poetics of Space, trans. Maria Jolas (Boston: Beacon Press, 1969 repr. 1994) p. 5.

${ }^{21}$ Patrizia Di Bello, Women's Albums and Photography in Victorian England: Ladies, Mothers and Flirts (Aldershot, Hamps: Ashgate, 2007) p. 145.

${ }^{22}$ Di Bello, pp. 72-4.

${ }^{23}$ Crary, Techniques of the Observer, p. 133.

24 'The Photograph', The Ladies' Cabinet of Fashion, September 1859.

25 'The Photograph'.

26 'The Photograph'.

27 'The Photograph'.

${ }^{28}$ Oliver Wendall Holmes, 'The Stereoscope and the Stereograph', in Atlantic Monthly, 1 June 1859, repr. in Classic Essays on Photography, ed. Alan Trachtenberg (New Haven, Conn.: Leete's Island Books, 1980) pp. 71 82 (p. 77).

29 'The Photograph'.

30 'Talk', Household Words, 15 April 1865, 284-8 (p. 284). 
${ }^{31}$ Di Bello, pp. 60-1.

${ }^{32}$ Charles Allston Collins, 'Her Face', Household Words, 28 August 1858, 258-64 (p. 258).

${ }^{33}$ Collins, p. 260.

${ }^{34}$ Collins, p. 262.

${ }^{35}$ Collins, p. 261.

${ }^{36}$ David Trotter suggests that there was a large number of women viewing such images as well as men (Trotter, p. 51). See also Colette Colligan, 'Stereograph', Victorian Review, 34, 1, (2008), 75-82; Linda Williams,

"Corporealized Observers: Visual Pornographies and the "Carnal Density of Vision"', in Fugitive Images: From Photography to Video, ed. Patrice Petro (Bloomington: Indiana University Press, 1995) pp. 3-41.

${ }^{37}$ W.J.T. Mitchell gives an importance account of temporal-spatial relations in image and text. See W.J.T. Mitchell, Iconology: Image, Text, Ideology (Chicago: University of Chicago Press, 1986) pp. 95-115.

${ }^{38}$ Mark Curie makes the point that oral fiction, especially if invented on the spot, has a more open future available to it. Currie draws attention to the ontological difficulties of narrative as a model for time which suggests some interesting avenues for considering the narrative relations of self-images in the stereoscope. See Mark Curie, About Time Narrative, Fiction and the Philosophy of Time (Edinburgh: Edinburgh University Press, 2007) pp. $17-8$.

${ }^{39}$ G. H. Lewes, 'Dickens in Relation to Criticism', The Fortnightly Review, February 1872, 141-54 (p. 144).

${ }^{40}$ Lewes, p. 145. 


\section{Appendix: Figures}

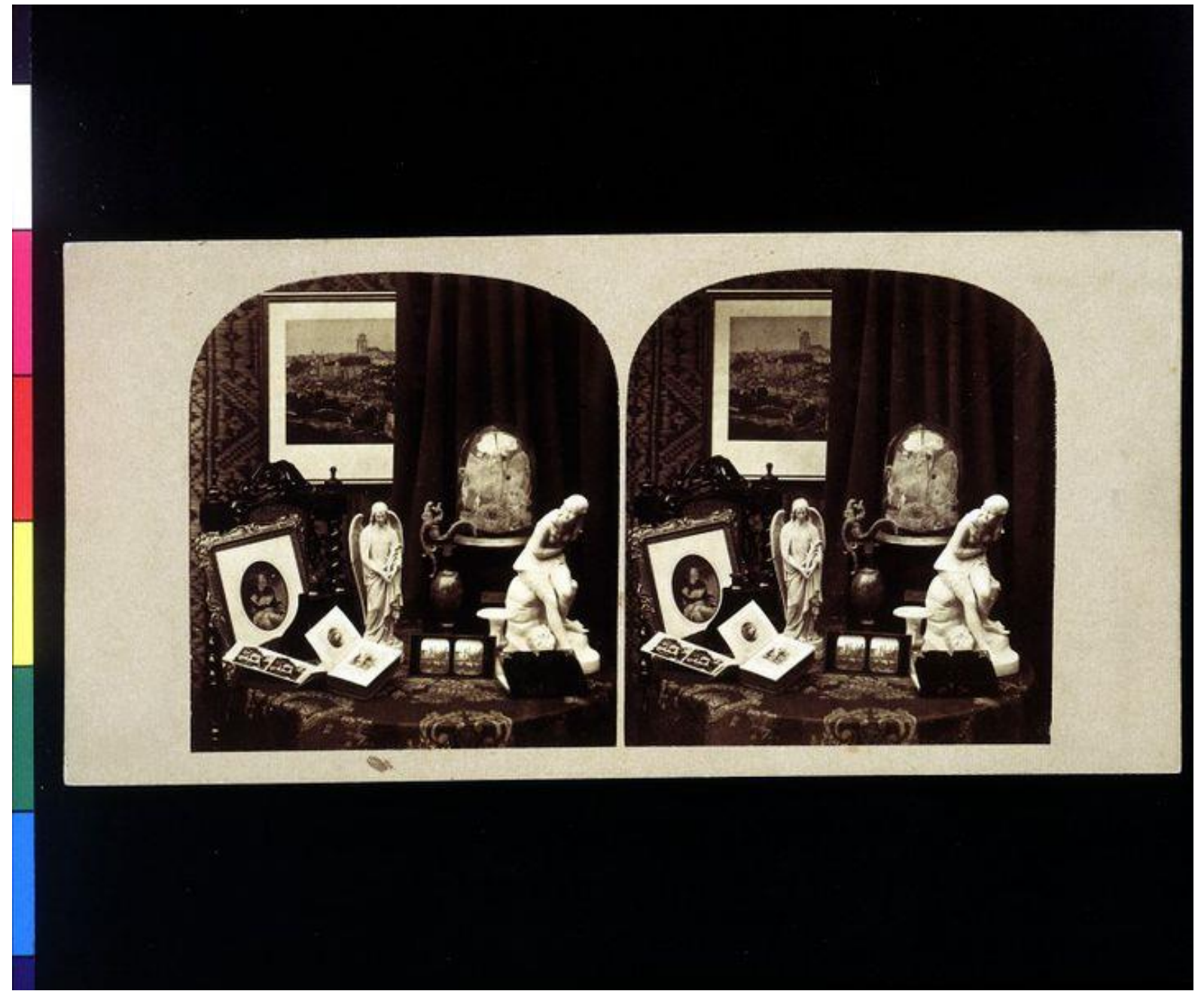

Figure 1. Still Life, c.1860-1870. Courtesy of Victoria and Albert Museum. 


\section{Works Cited}

'ART. VII. — Sight and Touch: An Attempt to Disprove the received (or Berkleian) Theory of Vision. By Thomas Abbott, M.A., Fellow and Tutor of Trinity College, Dublin. Illustrated with Woodcuts. London, 1864.' (Review) in The North British Review, 41, 81 (August 1864), 199-230.

Anon., 'So Like Matrimony', V anity Fair, 7 July 1860, 18.

Anon., 'Talk', Household Words, 15 April 1865, 284-8.

Anon., 'The Fancies of a Maiden Lady', The British Mothers' Journal, [Date Unknown].

Anon., 'The Photograph', The Ladies' Cabinet of Fashion, September 1859.

Armstrong, Isobel, Victorian Glassworlds: Glass Culture and the Imagination 1830-1880 (Oxford: Oxford University Press, 2008).

Armstrong, Nancy, Fiction in the Age of Photography: The Legacy of British Realism (London: Harvard University Press, 2002).

Bachelard, Gaston, The Poetics of Space, trans. Maria Jolas (Boston: Beacon Press, 1969 repr. 1994).

Byerly, Alison, Are We There Yet? : Virtual Travel and Victorian Realism (Ann Arbor, MI: University of Michigan Press, 2013).

Colligan, Colette, 'Stereograph', Victorian Review, 34, 1, (2008), 75-82.

Collins, Charles Allston, 'Her Face', Household Words, 28 August 1858, 258-64.

Crary, Jonathan, Suspensions of Perception: Attention, Spectacle, and Modern Culture (Cambridge, Mass.: MIT Press, 2001).

Curie, Mark, About Time Narrative, Fiction and the Philosophy of Time (Edinburgh: Edinburgh University Press, 2007).

Daguerre, Louis, 'Daguerreotype', in Classic Essays on Photography, ed. Alan Trachtenberg (New Haven, Conn.: Leete's Island Books, 1980), pp. 11-13.

Di Bello, Patrizia, Women's Albums and Photography in Victorian England: Ladies, Mothers and Flirts (Aldershot, Hamps: Ashgate, 2007).

Freeman, Mark, 'Telling Stories: Memory and Narrative', in Memory: Histories, Theories, Debates, ed. Susannah Radstone and Bill Schwarz (New York: Fordham University Press, 2010) pp. 263-77.

Gunning, Tom, 'The Exterior as Intérieur: Benjamin's Optical Detective', boundary 2, 30, 1 (2003), 105-130.

Hankins, Thomas L., and Robert J. Silverman, Instruments and the Imagination (Princeton, New Jersey: Princeton University Press, 1995). 
Holmes, Oliver Wendall, 'The Stereoscope and the Stereograph', in Atlantic Monthly, 1 June 1859, repr. in Classic Essays on Photography, ed. Alan Trachtenberg (New Haven, Conn.: Leete's Island Books, 1980) pp. 71-82.

Huhtamo, Erkki, Illusions in Motion: A Media Archaeology of the Moving Panorama and Related Spectacles (Cambridge, MA: MIT Press, 2013).

Jay, Bill, Cyanide and Spirits: An Inside-Out View of Early Photography (Munich: Nazraeli Press, 1991).

Lewes, G. H. 'Dickens in Relation to Criticism', The Fortnightly Review, February 1872, 141-54.

Mascher, J. F., 'On Taking Daguerreotypes without a Camera', Journal of the Franklin Institute, 59 (1855) 344-47 <http://www.sciencedirect.com/science/journal/00160032/59/5> [accessed: 27 November 2013].

Mitchell, W.J.T., Iconology: Image, Text, Ideology (Chicago: University of Chicago Press, 1986).

Morley, Henry, and William Henry Wills. 'Photography', Household Words, 19 March 1853, 54-61.

Morley, Henry, and William Henry Wills, 'The Stereoscope', Household Words, 10 September $1853,37-42$.

Nead, Lynda, 'Strip', Early Popular Visual Culture, 3, 2 (2005) 135-50.

Plunkett, John 'Depth, Colour, Movement: Embodied vision and the Stereoscope', in Multimedia Histories: From the Magic Lantern to the Internet, ed. James Lyons and John Plunkett (Exeter: University of Exeter Press, 2007) pp. 117-131.

Plunkett, John, “Feeling Seeing": Touch, Vision and the Stereoscope', History of Photography, 37, 4 (2013), 389-96.

Trotter, David, 'Stereoscopy: modernism and the "haptic", Critical Quarterly, 46, 4 (2004), 38-56.

Walter, Leslie, 'In a Stereoscope', Sharpe's London magazine of entertainment and instruction for general reading, August 1864, 83-89.

Williams, Linda, 'Corporealized Observers: Visual Pornographies and the "Carnal Density of Vision”", in Fugitive Images: From Photography to Video, ed. Patrice Petro (Bloomington: Indiana University Press, 1995) pp. 3-41. 